\title{
The Signature of the Coronavirus Lockdown in Air Pollution in Greece
}

\author{
Costas Varotsos 1 - John Christodoulakis • \\ George A. Kouremadas • Eleni-Foteini Fotaki
}

Received: 19 November 2020 / Accepted: 16 February 2021 / Published online: 9 March 2021

(C) The Author(s), under exclusive licence to Springer Nature Switzerland AG part of Springer Nature 2021

\begin{abstract}
The change in atmospheric pollution from a public lockdown in Greece introduced to curb the spread of the COVID-19 is examined based on ground-based and satellite observations. The results showed that in most cases, the change in atmospheric pollution is not statistically significant. It is probably an artifact of the meteorological conditions that contributed significantly to the long-range transport of air pollutants over Greece during the shutdown period.
\end{abstract}

Keywords Air pollution - COVID-19 - Satellite observations · Ground-based data · Greece

\section{Introduction}

Lockdowns applied worldwide to stop the spread of COVID-19 have aroused great interest in the scientific community due to the fact that the effects of air pollution resulting from these lockdowns are greater in some places than in others.

Ground-based and satellite observations over China-where the COVID-19 crisis began in late 2019 - and northern Italy, since January 2020, have shown signs of declining concentrations of air pollutants

C. Varotsos $(\bowtie) \cdot J$. Christodoulakis •

. A. Kouremadas · E.-F. Fotaki

Climate Research Group, Division of Environmental Physics and Meteorology, Faculty of Physics, National and Kapodistrian

University of Athens, University Campus Bldg. Phys. V,

15784 Athens, Greece

e-mail: covar@phys.uoa.gr harmful to human health, such as nitrogen dioxide $\left(\mathrm{NO}_{2}\right)$ which is emitted mainly by vehicles and power plants burning fossil fuels and is closely linked to morbidity and mortality (NASA 2020; Huang et al. 2020; $\mathrm{He}$ et al. 2020). A similar downward trend in these countries has been demonstrated by the atmospheric particle concentrations.

It should be noted that according to the World Health Organization, 4.6 millions of people die each year from diseases directly related to air quality (Cohen et al. 2017). More specifically, 193,000 people died in Europe in 2012 from airborne particles (Ortiz et al. 2017). In addition, air pollution in China is responsible for 4000 preventable deaths every day or 1.6 million deaths in 2016 (Wang et al. 2012; Rohde and Muller 2015). Considering the above-mentioned figures for the first 2 months of lockdown in China a reduction in air pollution could indicate a $6 \%$ reduction in mortality (i.e., about 100,000 people) (Dutheil et al. 2020; Varotsos and Krapivin 2020; Varotsos et al. 2021).

The changes observed in China and Italy were so large that they could not be explained by the variability caused by weather alone. In addition, the rapid spread of COVID-19 infection in selected areas of northern Italy is believed to be related to PM10 pollution due to airborne particles that may serve as carriers of pathogens (Setti et al. 2020).

The situation is more ambiguous when looking at the case of the USA, where air pollution has been reduced in the case of New York and other major cities due to COVID-19 lockdowns, but unlike most US cities a statistically significant change in air pollution. 
According to satellite data, the only city in the USA with a statistically significant improvement in air quality is Los Angeles, but there are skepticisms that the unusually heavy rainfall in recent weeks has contributed significantly (Schiermeier 2020).

Based on the above-mentioned experience, it should be of great interest to examine the impact of the lockdown applied in Greece in terms of air pollution, analyzing both ground-based and satellite data (Cracknell and Varotsos 2007; Cracknell and Varotsos 2011). This is the main purpose of the present paper.

\section{Data and Analysis}

For the purposes of this study, we used the available data gathered by the ground-based National Network for Monitoring Air Pollution operated by the Ministry of Environment \& Energy (MEE) and local authorities (e.g., municipalities /counties). Figure 1a shows the locations of the network stations used in this study, which are installed in the greater Athens area and operate by the MEE. Figure $1 \mathrm{~b}$ illustrates the locations of used stations installed in other major Greek cities operated by local authorities.

In this study, we focus on $\mathrm{NO}_{2}, \mathrm{O}_{3}, \mathrm{PM} 10$, and PM2.5 pollutants. Details of the measurements of each of them, such as the name of the station, the average measurement time, the measurement technique used for each pollutant, the equipment, and the unit of measurement, are given in Table 1.

According to this information, these four pollutants are not available for all stations. It should be noted that all the equipment listed in Table 1 has been officially approved by the European Environment Agency. The data is taken from the database of the European Environment Agency's (EEA) (https://discomap.eea.europa. eu/map/fme/AirQualityExport.htm, last access 18 /6/2020).

Satellite data have been retrieved from the Ozone Monitoring Instrument (OMI) database (last access 20/ 6/2020). Specifically, the following time series were used in this study : the average range of $\mathrm{NO}_{2}$ tropospheric column (OMNO2d_003_ColumnAmountNO2 TropCloudScreened) (last access 20/6/2020), the $\mathrm{SO}_{2}$ planetary boundary layer column amount (OMSO2e_003_ColumnAmountSO2_PBL) (last access 20/6/2020), the a Aerosol Optical Thickness (AOT) at $442 \mathrm{~nm}$ (OMAEROe_003_AerosolOpt icalThicknessMW_442_0) (last access 20/6/2020) and the Absorbing Aerosol Optical Thickness at $442 \mathrm{~nm}$ (OMAEROe_003_AbsorbingAerosolOpticalThicknessM W_442_0) (last access 20/6/2020) over the greater Athens basin and Thessaloniki. The data were obtained through the Giovanni web-based application developed by the Goddard Earth Sciences Data and Information Services Center (GES DISC) (Acker and Leptoukh 2007).

The daily data presented, cover the period from March 1 to June 10 of the years mentioned in each specific case.

\section{Results and Discussion}

\subsection{The Pattern of Air Quality in Greece}

In the urban and industrial areas of Greece, air pollution has been a serious environmental problem related to the rapid and anarchic urbanization of

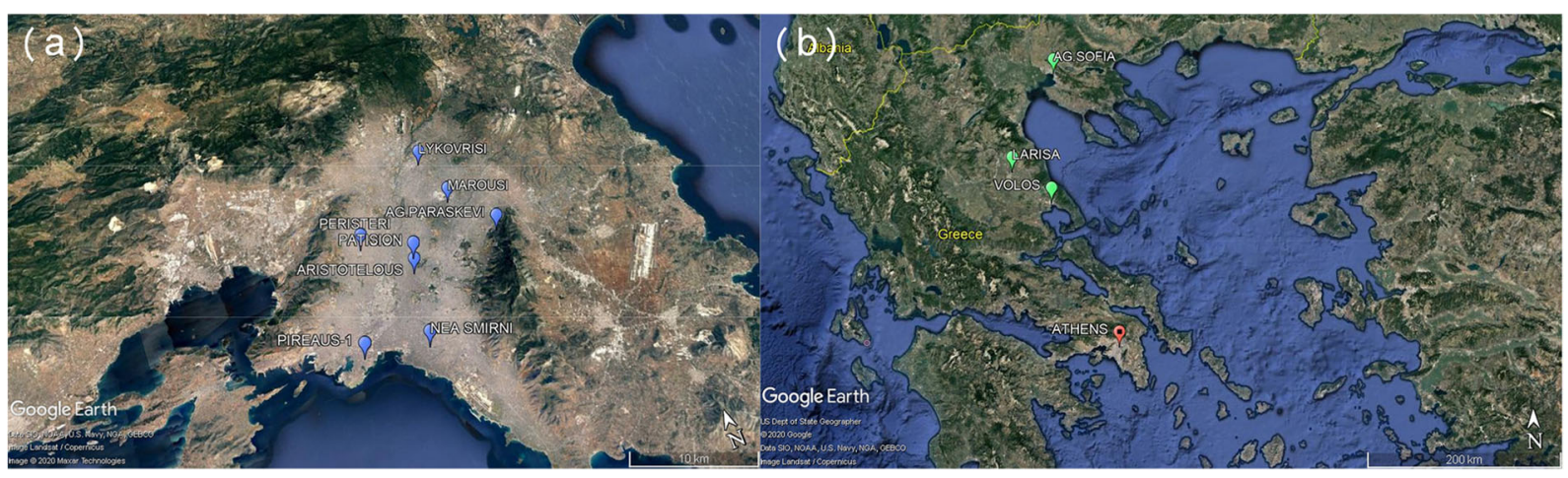

Fig. 1 a The ground-based National Air Pollution Monitoring Network located in the greater Athens area. b Ground-based stations for air pollution monitoring located at Thessaloniki, Volos and Larisa (source: Google Earth) 
Table 1 Information on each of the pollutants investigated in this study

\begin{tabular}{|c|c|c|c|c|c|}
\hline Pollutant & Station name & $\begin{array}{l}\text { Average measurement } \\
\text { time }\end{array}$ & Equipment & $\begin{array}{l}\text { Measurement } \\
\text { technique }\end{array}$ & $\begin{array}{l}\text { Concentration } \\
\text { units }\end{array}$ \\
\hline \multirow[t]{7}{*}{$\mathrm{NO}_{2}$} & $\begin{array}{l}\text { Ag.Paraskevi } \\
\text { Ag.Sofia-Thessaloniki }\end{array}$ & \multirow[t]{7}{*}{ Hour } & Horiba APNA 360E & \multirow[t]{7}{*}{ Chemiluminescence } & \multirow[t]{7}{*}{$\mu \mathrm{g} / \mathrm{m}^{3}$} \\
\hline & $\begin{array}{l}\text { Aristotelous } \\
\text { Lykovrisi }\end{array}$ & & \multirow[t]{6}{*}{ Teledyne API 200} & & \\
\hline & Marousi & & & & \\
\hline & Nea Smirni & & & & \\
\hline & Patision & & & & \\
\hline & Peristeri & & & & \\
\hline & Pireaus-1 & & & & \\
\hline \multirow[t]{7}{*}{$\mathrm{O}_{3}$} & $\begin{array}{l}\text { Ag.Paraskevi } \\
\text { Lykovrisi }\end{array}$ & \multirow[t]{7}{*}{ Hour } & \multirow[t]{6}{*}{$\begin{array}{l}\text { Teledyne API 400A (for } \\
\text { Ag.Paraskevi) }\end{array}$} & \multirow[t]{7}{*}{$\begin{array}{l}\text { Ultraviolet } \\
\text { absorption }\end{array}$} & \multirow[t]{7}{*}{$\mu \mathrm{g} / \mathrm{m}^{3}$} \\
\hline & Marousi & & & & \\
\hline & Nea Smirni & & & & \\
\hline & Patision & & & & \\
\hline & Peristeri & & & & \\
\hline & Pireaus-1 & & & & \\
\hline & Ag.Sofia-Thessaloniki & & Horiba model APOA 360 & & \\
\hline \multirow[t]{9}{*}{ PM10 } & $\begin{array}{l}\text { Ag.Paraskevi } \\
\text { Aristotelous }\end{array}$ & \multirow[t]{9}{*}{ Hour } & \multirow[t]{9}{*}{ MetOne BAM-1020 } & \multirow[t]{9}{*}{ Beta ray attenuation } & \multirow[t]{9}{*}{$\mu \mathrm{g} / \mathrm{m}^{3}$} \\
\hline & Lykovrisi & & & & \\
\hline & Marousi & & & & \\
\hline & Nea Smirni & & & & \\
\hline & Peristeri & & & & \\
\hline & Pireaus-1 & & & & \\
\hline & Ag.Sofia-Thessaloniki & & & & \\
\hline & Larisa & & & & \\
\hline & Volos & & & & \\
\hline \multirow[t]{5}{*}{ PM2.5 } & $\begin{array}{l}\text { Ag.Paraskevi } \\
\text { Aristotelous }\end{array}$ & \multirow[t]{5}{*}{ Hour } & \multirow[t]{5}{*}{ MetOne BAM-1020 } & \multirow[t]{5}{*}{ Beta ray attenuation } & \multirow[t]{5}{*}{$\mu \mathrm{g} / \mathrm{m}^{3}$} \\
\hline & Lykovrisi & & & & \\
\hline & Pireaus-1 & & & & \\
\hline & Ag.Sofia-Thessaloniki & & & & \\
\hline & Volos & & & & \\
\hline
\end{tabular}

cities and the increase of motor vehicles, central heating, and industrial facilities. In the 1960 s and 1970 s, there were serious problems with air pollution, especially in Athens (Varotsos and Cartalis 1991; Chattopadhyay et al. 2012; Varotsos et al. 2014). In most urban areas (e.g., Athens and Thessaloniki), air quality has improved significantly in recent years, mainly due to the replacement of polluting vehicles of old technology with those equipped with catalytic converters; hence, the environmental levels of smoke, $\mathrm{CO}, \mathrm{SO}_{2}, \mathrm{NOx}\left(\mathrm{NO}_{2}\right.$, $\mathrm{NO}$ ), and $\mathrm{O}_{3}$ decreased significantly. Policy reduction practices have effectively reduced primary $\left(\mathrm{SO}_{2}, \mathrm{NOx}, \mathrm{CO}\right.$, smoke) and secondary $\left(\mathrm{O}_{3}\right)$ pollutants. However, the economic crisis of recent years (2010-2018) has forced some residents to use low- 

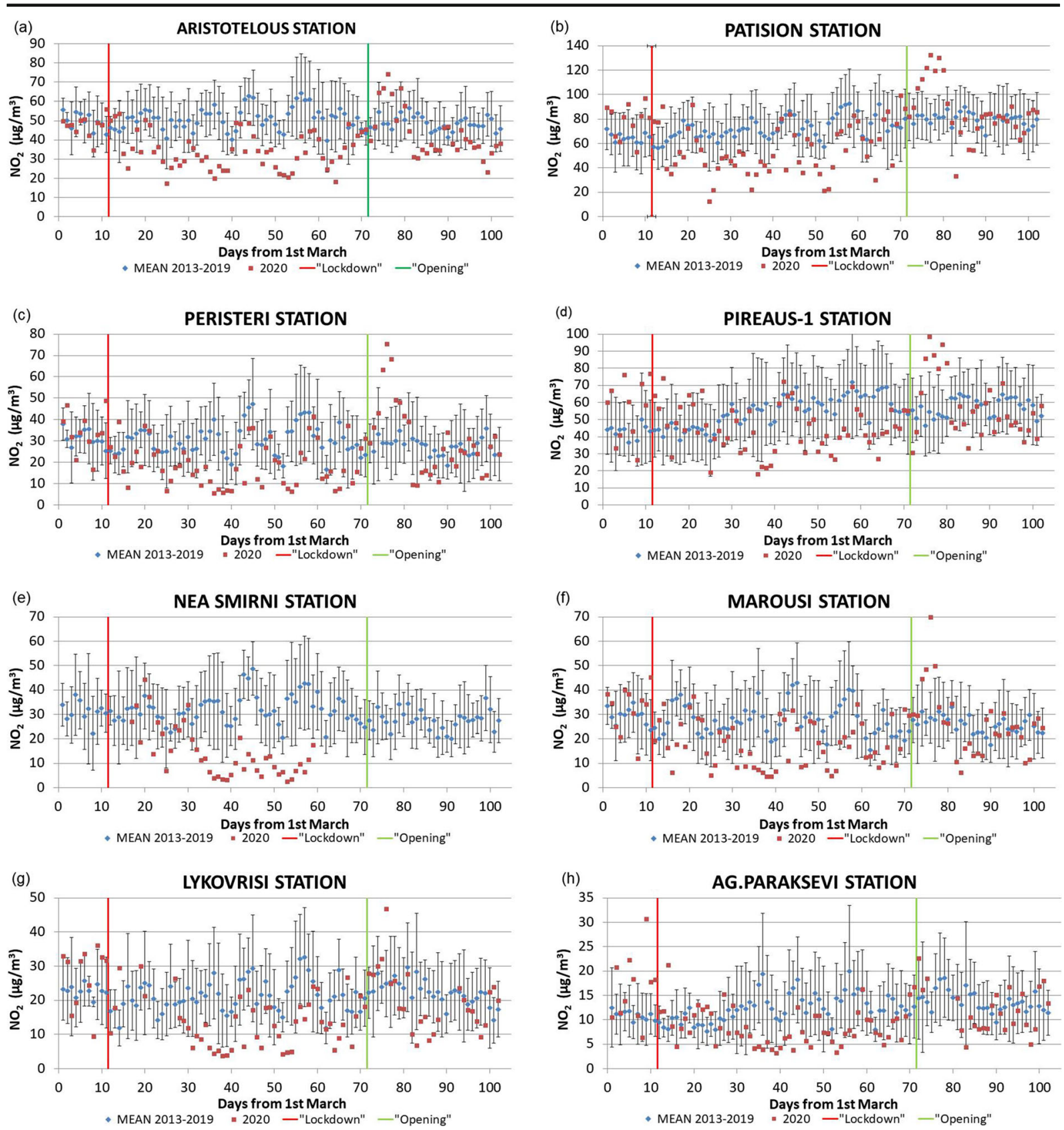

Fig. 2 The average daily concentration of $\mathrm{NO}_{2}$ in different stations (Aristotelous (a), Patision (b), Peristeri (c), Pireaus-1 (d), Nea Smirni (e), Marousi (f), Lykovrisi (g), and Ag. Paraskevi (h)) of the groundbased network located in the greater Athens area before, during and after the national lockdown due to the Coronavirus disease (COVID-

cost wood and biomass as fuel for fireplaces and stoves, resulting in fog and high levels of airborne particles that are dangerous due to their toxic organic compounds, free radicals, and metals.

19) outbreak (red dots), along with the long-term mean observed in

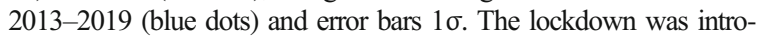
duced on March 12 (red vertical line) and the first part of the opening was on May 11 (green vertical line)

3.2 The Pattern of the Air Quality in Athens

In particular, the high population density, the intense sunshine, and the special topography — a basin surrounded by 
mountains - create in the city of Athens and in the wider area air pollution problems characterized by the following:

- Since 1984, there has been a decrease in the concentrations of certain air pollutants and mainly primary pollutants, such as $\mathrm{CO}$ and $\mathrm{SO}_{2}$.

- The issue of air pollution in Athens focuses mainly on tropospheric $\mathrm{O}_{3}$ produced by the combination of intense sunshine with ozone precursors.

- The PM10 concentration exceeds limits for more than $24 \mathrm{~h}$ in some stations, mainly due to the dust transported from Sahara.

- Higher concentrations of $\mathrm{SO}_{2}, \mathrm{NO}_{2}$ and $\mathrm{CO}$ are observed in the city center. Exceeding the annual $\mathrm{NO}_{2}$ limit was observed in limited locations. $\mathrm{SO}_{2}$ and $\mathrm{CO}$ concentrations during the winter are higher than in the summer. Maximum $\mathrm{CO}$ values coincide with traffic peaks.

- The combination of topography, low mixing height, and weak local southwest winds (sea breeze effect) often leads to $\mathrm{O}_{3}$ accumulation in the northern and northeastern suburbs, especially during the summer afternoon. Thus, $\mathrm{O}_{3}$ concentrations are usually higher in suburban locations.

As mentioned in the Introduction, epidemiological studies in European cities have documented correlations between exposure to biomass combustion products, air pollutants, and some adverse health effects.

3.3 The Impact to the Air Pollution of the COVID-19 Lockdown: the Case of Athens

As of March 10, the government suspended all educational institutions nationwide and then, on March 13, proceeded with closing all cafes, bars, museums, shopping malls, sports facilities, and restaurants in the country. On March 16, all retail stores and places of worship were also closed. Additionally, from 6 p.m. on March 23, all unnecessary travels across the country were restricted. On April 4, these restrictions were extended until April 27, and on April 23, they were extended once again until May 4. A final extension by May 10 was decided by the government authorities. May 11 is considered the first day of the partial withdrawal of the restrictive measures.

Under these conditions, levels of air pollution are expected to have dropped significantly. In the following, we use the available air pollution measurements to verify this expectation.

\subsubsection{Nitrogen Dioxide}

Only about $1 \%$ of the total amount of $\mathrm{NO}_{2}$ found in cities' air is formed naturally, by lightning, plants, soil, and water. It is a key air pollutant contributing to the formation of photochemical smog. The main source of this is the burning of fossil fuels, and when it comes to cities, it comes mainly from the motor vehicle emissions. Its other sources are petrol and metal refining, electricity generation from coal-fired power stations, other manufacturing industries, and food processing.

Ground-Based Data Figure 2 shows the $\mathrm{NO}_{2}$ levels in the greater area of the Athens basin as derived from the measurements of the ground-based air pollution monitoring network stations located in the region. The time period of the $\mathrm{NO}_{2}$ concentrations presented is 1 March, a few days before lockdown until 10 June 2020. For comparison reasons, these $\mathrm{NO}_{2}$ concentrations levels are plotted together with those reflecting the normal $\mathrm{NO}_{2}$ concentrations of the entire available record in EEA database, i.e., 2013-2019. The inspection of Fig. 2 reveals that the reduction of $\mathrm{NO}_{2}$ levels during the lockdown period does not indicate a clear step-by-step or rapid reduction that could be expected after the abrupt application of shutdown. It is noteworthy that the $\mathrm{NO}_{2}$ concentrations during lockdown are in many cases into the standard deviation zone of its normal long-term levels or close to their lowest limits. Except for a short period, about 10 days after the start of the withdrawal measures, i.e., the "opening", when high $\mathrm{NO}_{2}$ concentration values were observed in almost all stations, the mean daily concentration values followed the same pattern as the "lockdown" period. In most of the days studied after opening, the observed $\mathrm{NO}_{2}$ concentrations fall within the range $1 \sigma$ of the 2013-2019 mean value.

Satellite Data The above-mentioned result obtained from the ground-based $\mathrm{NO}_{2}$ concentrations is confirmed by the $\mathrm{NO}_{2}$ satellite observations illustrated in Fig. 3 . More specifically, no clear lockdown signal is detected at the $\mathrm{NO}_{2}$ concentrations in the wider Athens area by satellite observations. Most of the $\mathrm{NO}_{2}$ observations lie within the range $(\mu-1 \sigma, \mu+1 \sigma)$ leading to the conclusion that the claim that the lockdown period favored the environment due to the reduction of air pollution is not sufficiently confirmed in the case of Athens. 


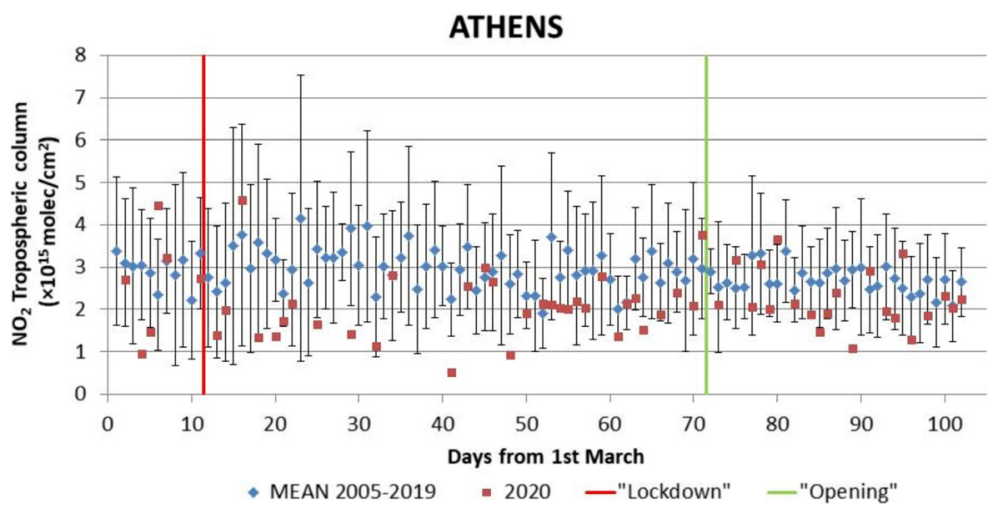

Fig. 3 Time series of daily mean area averaged $\mathrm{NO}_{2}$ tropospheric column density over greater Athens basin before, during and after national lockdown due to coronavirus disease (COVID-19) outbreak (red dots), along with the long term mean observed during

\subsubsection{Ozone from Ground-Based Data}

Surface $\mathrm{O}_{3}$ is a secondary air pollutant formed by a series of chemical reactions in the presence of sunlight. The photochemical reactions of nitrogen oxides and volatile organic compounds (which include various hydrocarbons) govern the concentration of ground-level $\mathrm{O}_{3}$ in the atmosphere. The time required to carry out these reactions varies from hours to days. Episodes of
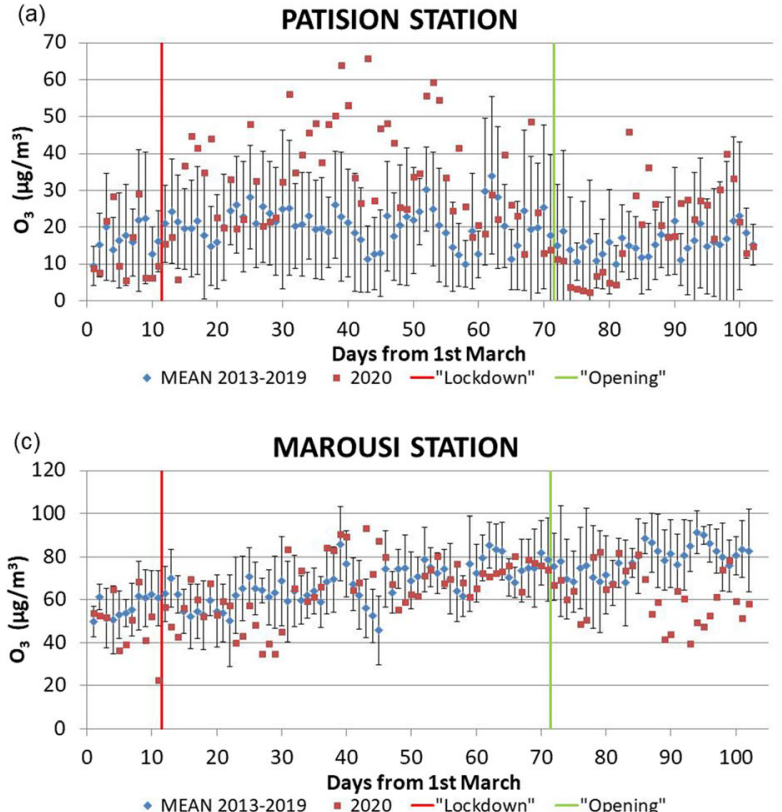

Fig. 4 The average daily concentration of $\mathrm{O}_{3}$ at different stations (Patision (a), Pireaus-1 (b), Marousi (c), and Ag. Paraskevi (d)) of the ground-based network located in the greater Athens area before, during, and after the national lockdown due to the
2005-2019 (blue dots) and the $1 \sigma$ error bars. The lockdown was introduced on March 12 (red vertical line) and the first part of the opening was on May 11 (green vertical line)

air pollution or smog occur when high concentrations of precursors (e.g,. $\mathrm{O}_{3}>40 \mathrm{ppb}$ ) coincide with weather conditions favorable for $\mathrm{O}_{3}$ production such as when the air is warm and slow moving.

Figure 4 shows the $\mathrm{O}_{3}$ surface levels in the greater Athens basin before, during, and after the lockdown period together with the long-term normal ozone concentration coming from the entire data archive. The conclusion drawn from Fig. 4 is that there is no clear
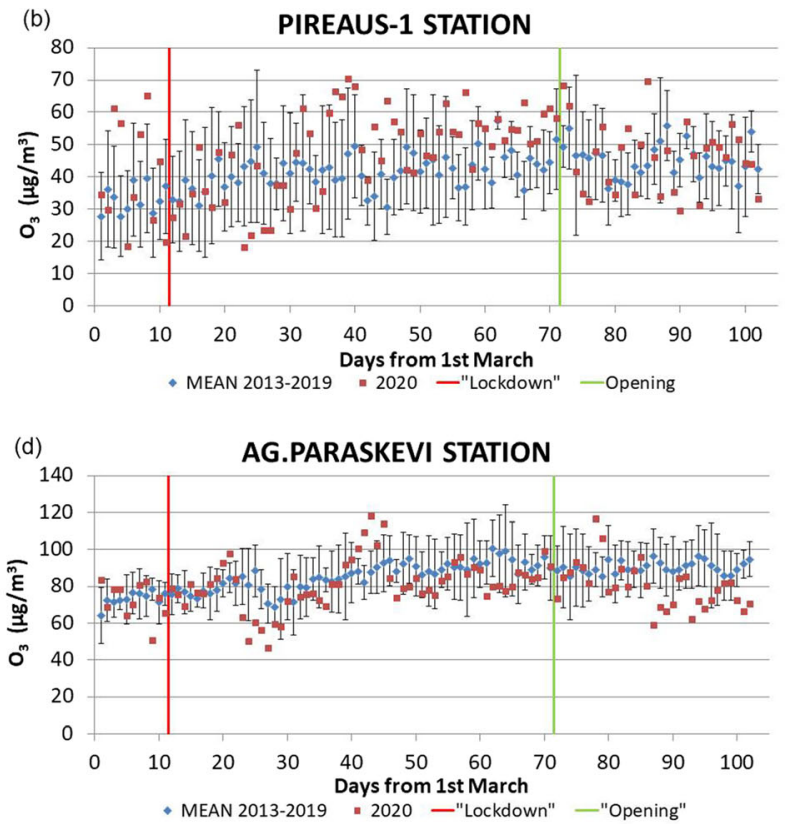

coronavirus disease (COVID-19) outbreak (red dots), along with the long-term mean observed in 2013-2019 (blue dots) and the $1 \sigma$ error bars. Red and green lines as in Fig. 2 

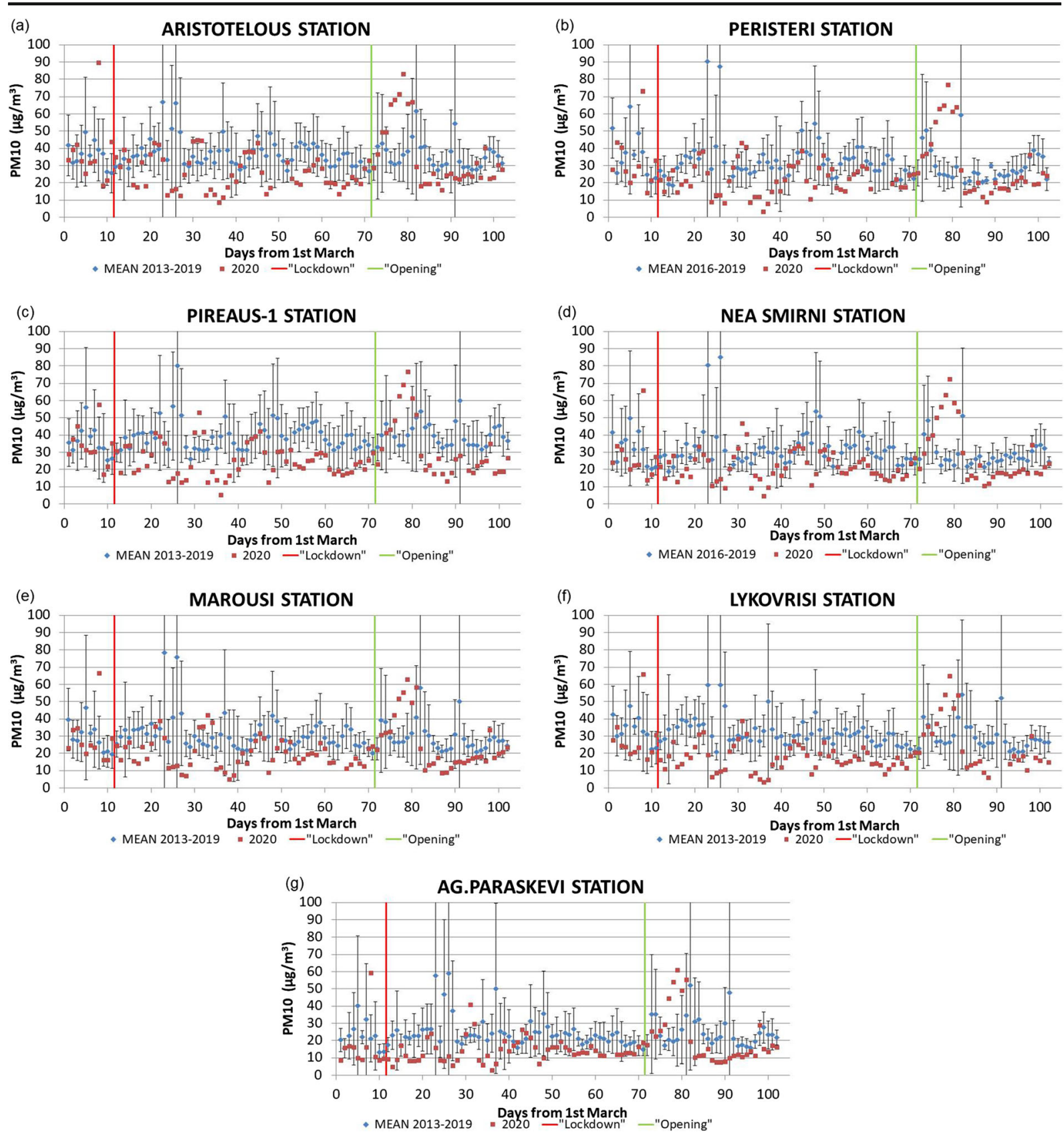

Fig. 5 The average daily concentration of PM10 at different stations (Aristotelous (a), Persiteri (b), Pireaus-1 (c), Nea Smirni (d), Marousi (e), Lykovrisi (f), and Ag. Paraskevi (g)) of the ground-based network located in the greater Athens area before,

indication that surface $\mathrm{O}_{3}$ levels have declined during the lockdown period. Particularly, most of the observations are within the range of the one standard deviation limits or higher. It should be recalled here that $\mathrm{O}_{3}$ levels at a particular location may have originated from the during, and after the national lockdown due to the coronavirus disease (COVID-19) outbreak (red dots), along with the long-term mean observed in 2013-2019 (blue dots) and the $1 \sigma$ error bars. Red and green lines as in Fig. 2

emissions of nitrogen oxides and volatile organic compounds that have taken place hundreds or even thousands of kilometers away. Most likely, this transport mechanism is dominated by reducing the expected sharp decrease in $\mathrm{O}_{3}$ levels during the lockdown period. 

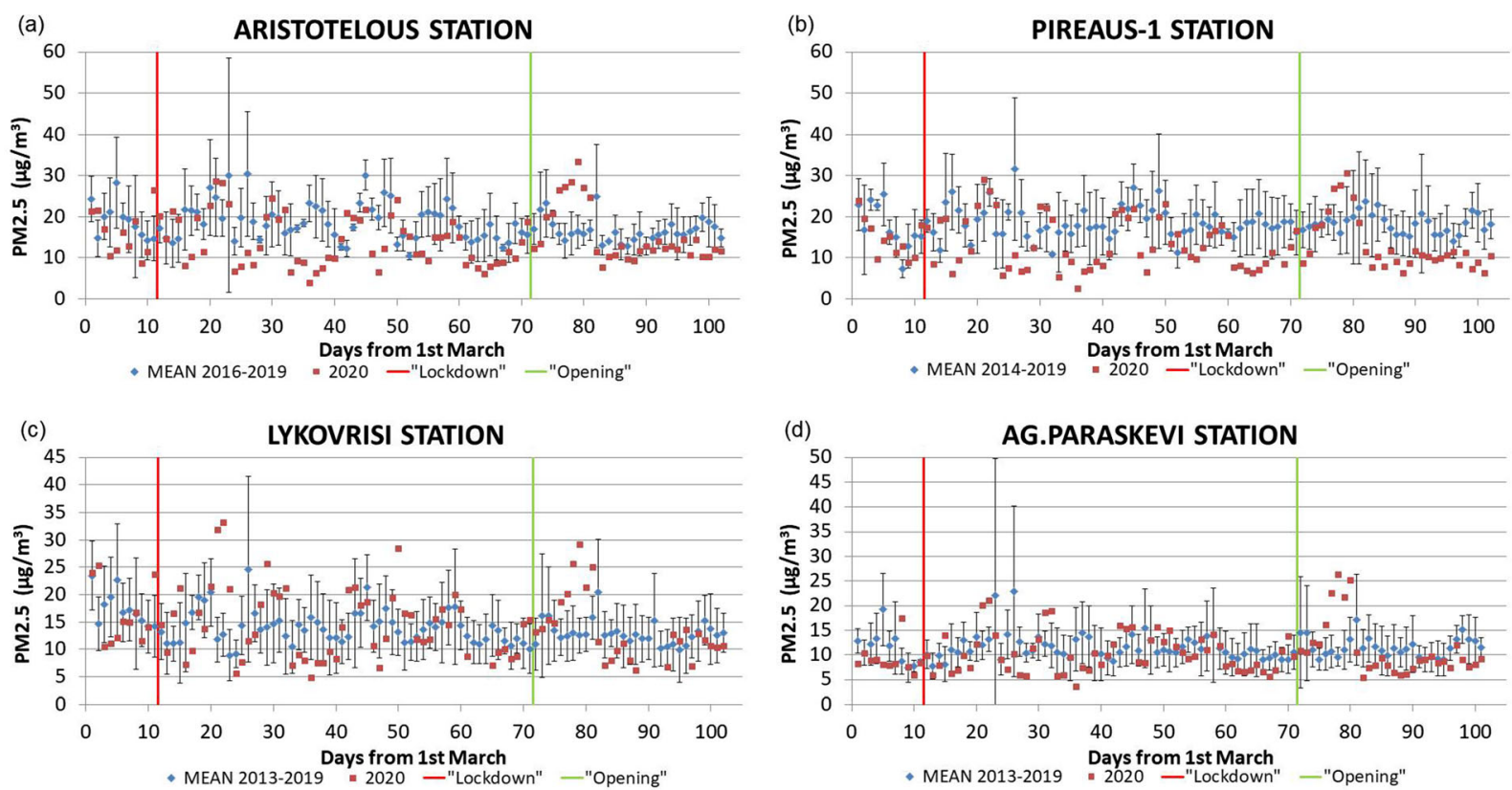

Fig. 6 The average daily concentration of PM2.5 at different stations (Aristotelous (a), Pireaus-1 (b), Lykovrisi (c), and Ag. Paraskevi (d)) of the ground-based network located in the greater Athens area before, during, and after the national lockdown due to the coronavirus disease

(COVID-19) outbreak (red dots), along with the long-term mean observed in 2013-2019 (blue dots) and the $1 \sigma$ error bars. Red and green lines as in Fig. 2

\subsubsection{PM10 from Ground-Based Data}

Briefly describing the PM10, we may say that it is a particulate matter (mixture of solid particles and liquid

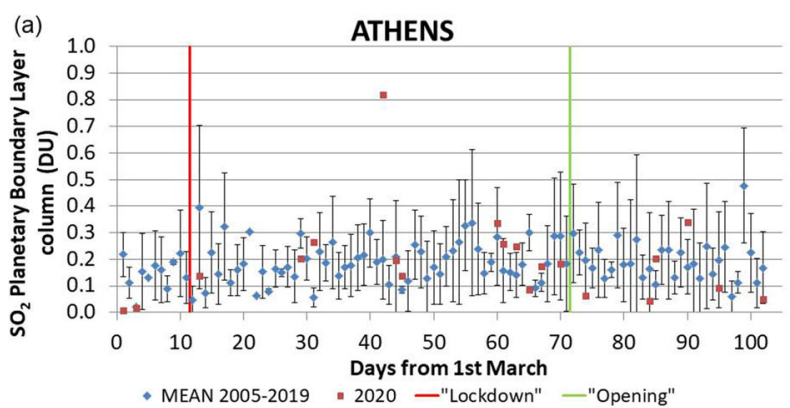

droplets) $10 \mu \mathrm{m}$ or less in diameter, causing a decrease in visibility. It should be clarified that PM10 is a particle size classification, and its chemical properties vary depending on the particles' sources. PM10 can be either
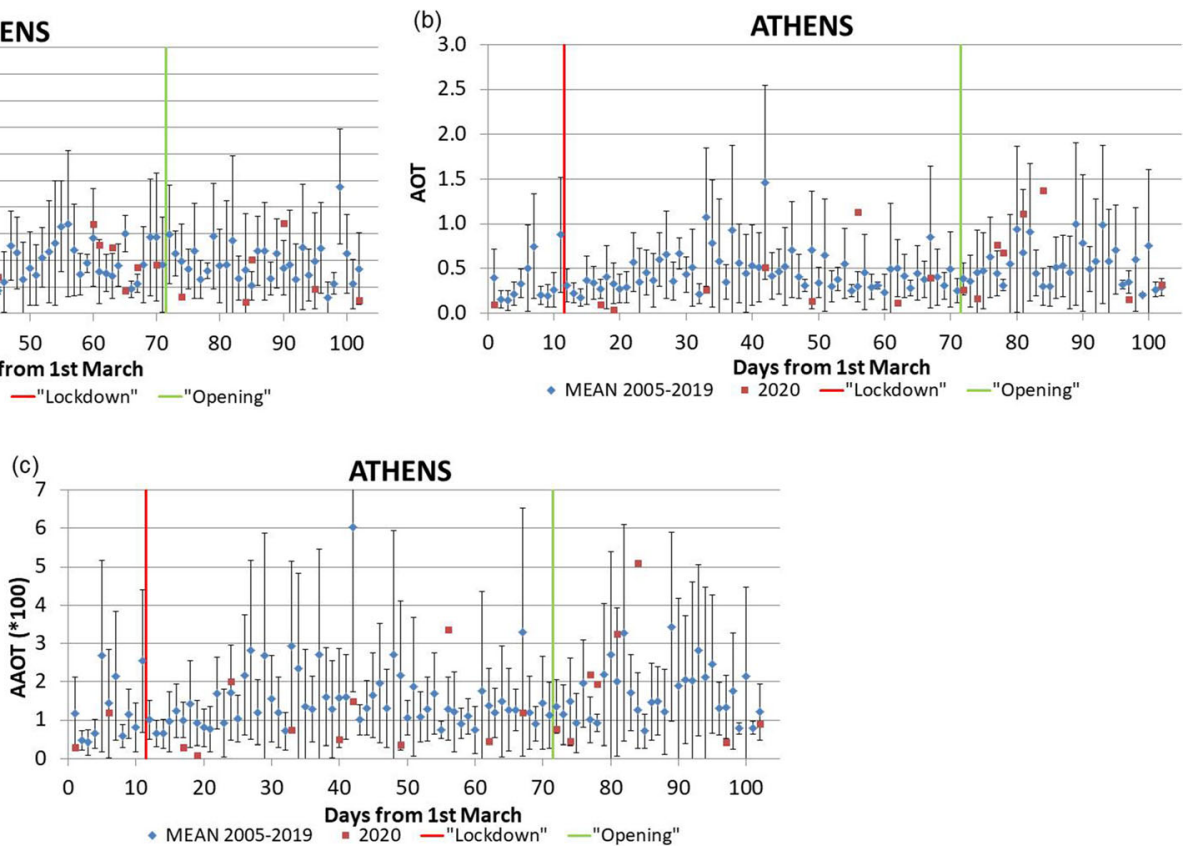

Fig. 7 Time series of the daily mean area averaged $\mathrm{SO}_{2}$ planetary boundary layer density (a), AOT (b), and AAOT (c) in the greater Athens basin before, during, and after national lockdown due to coronavirus disease (COVID-19) outbreak. The symbols and lines are as in Fig. 3 

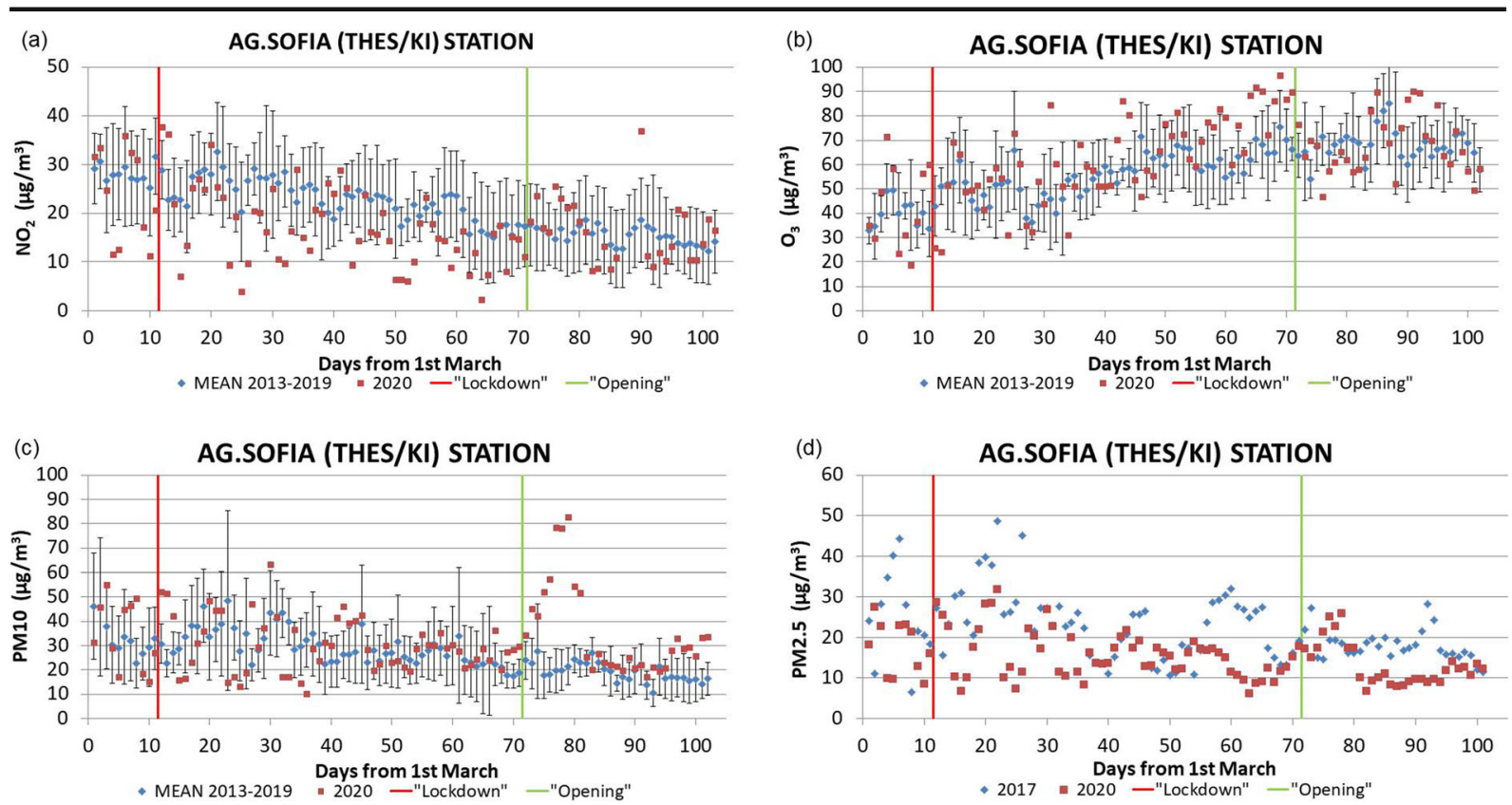

Fig. 8 The daily mean concentrations of $\mathrm{NO}_{2}(\mathbf{a}), \mathrm{O}_{3}(\mathbf{b}), \mathrm{PM} 10$ (c), and PM2.5 (d) in Ag. Sofia station located in Thessaloniki before, during, and after national lockdown due to coronavirus disease (COVID-19) outbreak. The symbols and lines are as in Fig. 2

anthropogenic or natural. Among their common sources are dust from unsealed roads, smoke from fires, sea salt, car and truck exhausts, and industry.
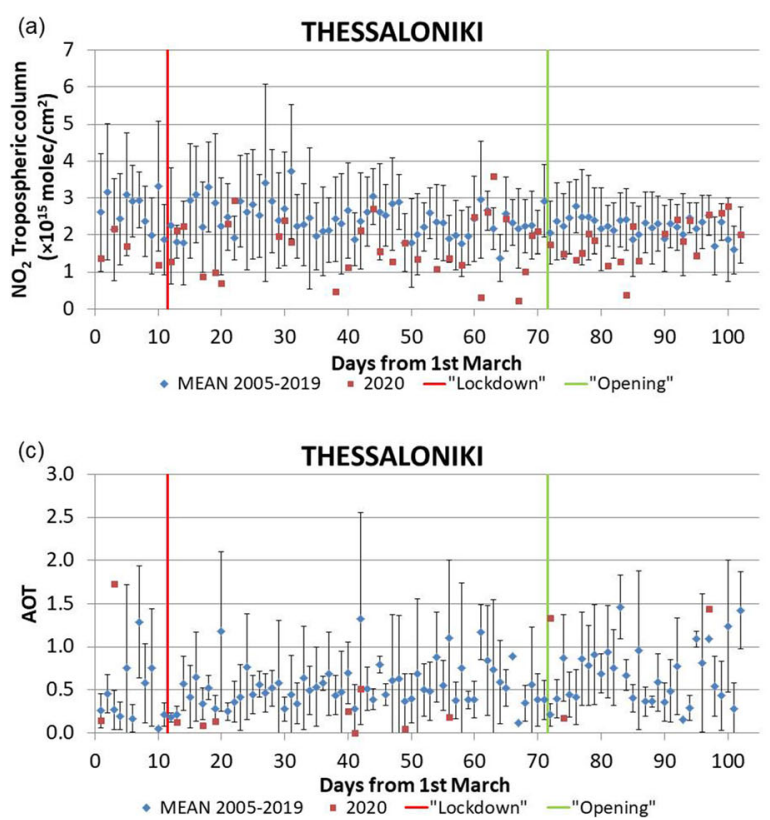

Fig. 9 Time series of the daily mean area averaged NO2 tropospheric column density (a), $\mathrm{SO}_{2}$ planetary boundary layer density (b), AOT (c), and AAOT (d) in the greater Thessaloniki area
Figure 5 shows the temporal evolution of PM10 before, during, and after the lockdown period at several monitoring stations in the wider Athens ba-
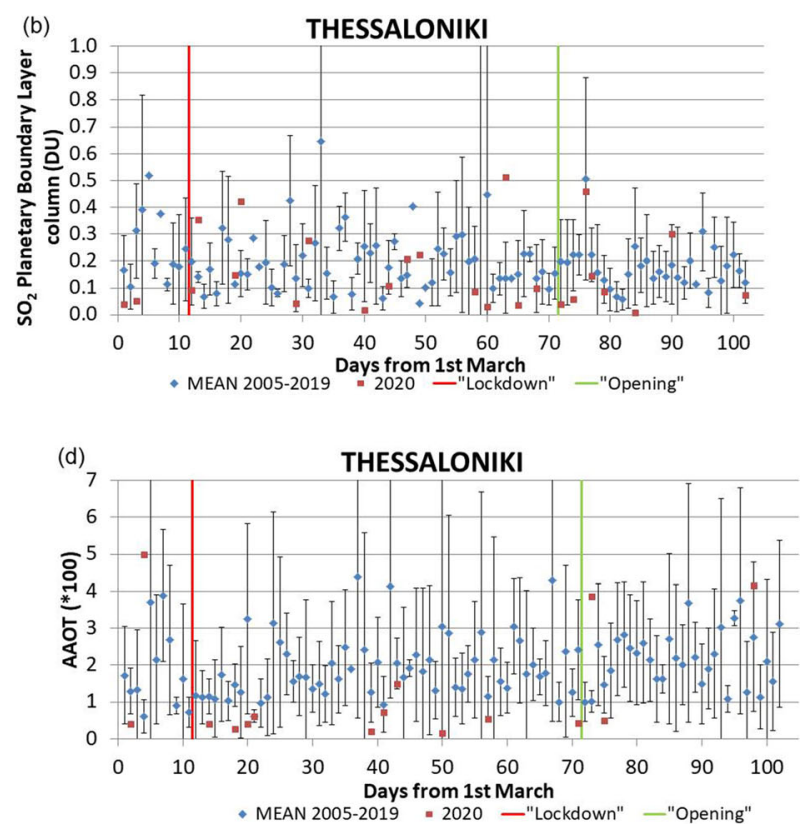

before, during, and after national lockdown due to coronavirus disease (COVID-19) outbreak. The symbols and lines are as in Fig. 3 

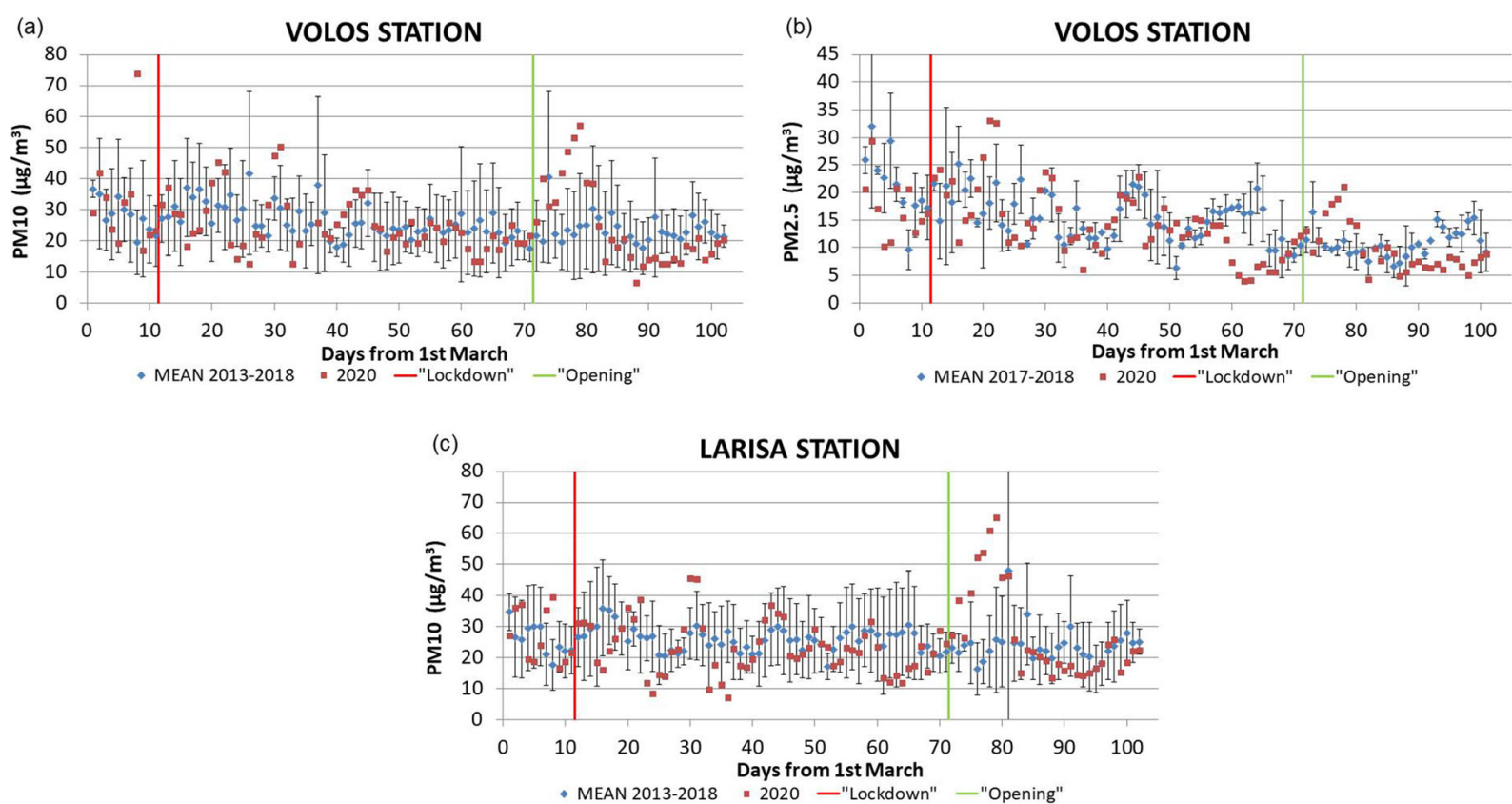

Fig. 10 PM10 (a) and PM2.5 (b) daily mean concentrations in Volos and PM10 daily mean concentration in Larisa (c) before, during, and after national lockdown due to the occurrence of coronavirus disease (COVID-19). The symbols and lines are as in Fig. 2

sin along with the long-term normal PM10 for comparison purposes. Inspection of Fig. 5 shows that no significant change in the PM10 concentration was observed during the lockdown period.

\subsubsection{PM2.5 from Ground-Based Data}

Particulate matter PM2.5 or fine particulate matter means the mass of particles per $\mathrm{m}^{3}$ of air with a size (diameter) generally less than $2.5 \mu \mathrm{m}$. The most important sources of PM2.5 are human-made compared to natural ones, which have a small contribution to the overall concentration. For example, in cities, an important source of PM2.5 is road vehicles. In some places, industrial emissions can also be significant, such as the use of nonsmokeless fuels for heating and other domestic sources of smoke such as bonfires. Long-range transport, together with pollution from local sources, can lead to short-term high pollution episodes. In addition to these direct (i.e., primary) emissions of particles, PM2.5 can also be formed by chemical reactions of gases such as $\mathrm{SO}_{2}$ and nitrogen oxides.

The measurements of the PM2.5 in some representative monitoring stations in the Athens basin during the lockdown period do not show a significant decline (Fig. 6). It is probably an indication that the long-range transport mechanism has prevailed.

\subsection{5 $\mathrm{SO}_{2}$, AOT, AAOT, from Satellite Data}

$\mathrm{SO}_{2}$ is formed during the combustion of fuel containing S, such as coal and oil. It is also emitted by trains, large ships, and some diesel equipment that burns high $\mathrm{S}$ fuel and volcanic eruptions. It is a common air pollutant that is found especially in summer smog. $\mathrm{SO}_{2}$ and nitrogen oxides affect the environment when they react with substances in the atmosphere to form acid rain.

Satellite observations monitor aerosol optical thickness (AOT) and absorption AOT (AAOT) in two and three dimensions to understand the evolution of natural and anthropogenic aerosol plumes. These observations are based on the fact that the atmospheric particles alter the way the atmosphere reflects/absorbs visible and infrared light. Figure 7 shows the satellite observations conducted by OMI instrument of $\mathrm{SO}_{2} \mathrm{AOT}$, and AAOT over the Athens basin during the lockdown period, where no significant change was observed compared to their respective long-term variability. 
3.4 The Impact on Air Pollution of the COVID-19

Lockdown: the Case of Thessaloniki

\subsubsection{Ground-Based Data}

Figure 8 shows the level of $\mathrm{NO}_{2}, \mathrm{O}_{3}, \mathrm{PM} 10$, and PM2.5 concentrations during the lockdown period in the city of Thessaloniki, as derived from the observations recorded at Agia Sofia station which belongs to the National Network of Air Pollution Monitoring Stations. For comparative purposes, Fig. 8 also shows the long-term variability of these pollutants. Remarkably, there is no particular difference in air quality despite the restrictive lockdown measures.

\subsubsection{Satellite Data}

Given that satellite data has greater spatial coverage, it would be interesting to analyze satellite observations for the geographical coordinates of Thessaloniki city. The results obtained are shown in Fig. 9, where the $\mathrm{NO}_{2}$, $\mathrm{SO}_{2}$, AOT, and AAOT patterns are displayed for the lockdown period compared to their long-term mean pattern. From Fig. 9 is obvious that the data values during the lockdown period belong into the variability interval of their long-term mean, thus declaring that there was no decrease during the lockdown period.

\subsection{The Impact of the COVID-19 Lockdown on Air} Pollution: the Case of Volos and Larisa

Figure 10 presents PM10 and PM2.5 data recorded by the ground-based instrumentation of the Volos and Larisa stations that belong to the National Network of Air Pollution Monitoring Stations and are operated by the local authorities. An inspection of this figure reveals that there is no statistical difference between the values collected during the lockdown period and their longterm mean. It is clear evidence that the combination of meteorological regime prevailed, and the long-range transport of particulate matter during the lockdown period resulted in the coverage of any reduction signal due to limited anthropogenic activity.

\section{Conclusions}

The purpose of this study was to investigate how much cleaner the air was above Greece due to the coronavirus shutdown, using observations made from both ground- based and satellite-borne instruments. The results obtained can be summarized as follows:

In most cases, there has been no statistically significant reduction in air pollution in Greece, if the air pollution levels are compared to the long-term mean pollution records of the last 7 years (for most of the cases presented). This may be attributed to the meteorological conditions that prevailed during the coronavirus shutdown period which contributed significantly. For example, meteorological conditions are governed by non-linear dynamics, obeying scaling phenomena affecting air pollution in the same way (Efstathiou and Varotsos 2010, 2012; Efstathiou et al. 2011; Varotsos et al. 2013)

The lockdown introduced, objectively slowed the spread of Covid-19, regardless of whether it also caused significantly reduced air pollution. In countries with significantly reduced air pollution, the question arisen is how many lives have been saved as a result of reduced pollution? In the case of China, about 12,125 deaths were prevented during China's countrywide ban on traffic mobility between February 10 and March 14. According to a recently published study, this is higher than the lives lost to the pandemic - 4,633 as of May 4 (Chen et al., 2020).

In any case, because exposure to air pollution is known to damage the heart and lungs, it increases the vulnerability to more serious coronavirus effects. For example, a small increase in long-term exposure to fine particulate matter (PM2.5) leads to a large increase in the coronavirus death rate (e.g., just $1 \mu \mathrm{g} / \mathrm{m}^{3}$ to particulates corresponded to a $15 \%$ increase in COVID-19 deaths).

Acknowledgment Authors would like to acknowledge the OMI mission scientists and associated NASA personnel for the production of the data used in this research effort. Authors would also like to acknowledge the European Environment Agency (EEA) for the collection and distribution of ground-based data. This research did not receive any specific grant from funding agencies in the public, commercial, or not-for-profit sectors.

\section{References}

Acker, J. G., \& Leptoukh, G. (2007). Online analysis enhances use of NASA Earth Science data. EOS. Transactions of the American Geophysical Union, 88(2), 14. https://doi. org/10.1029/2007EO020003.

Chattopadhyay, G., Chakraborthy, P., \& Chattopadhyay, S. (2012). Mann-Kendall trend analysis of tropospheric ozone 
and its modeling using ARIMA. Theoretical and Applied Climatology, 110(3), 321-328. https://doi.org/10.1007 /s00704-012-0617-y.

Cohen, A. J., Brauer, M., Burnett, R., Anderson, H. R., Frostad, J., Estep, K., Balakrishnan, K., Brunekreef, B., Dandona, L., Dandona, R., Feigin, V., Freedman, G., Hubbell, B., Jobling, A., Kan, H., Knibbs, L., Liu, Y., Martin, R., Morawska, L., Pope, C. A., Shin, H., Straif, K., Shaddick, G., Thomas, M., van Dingenen, R., van Donkelaar, A., Vos, T., Murray, C. J. L., \& Forouzanfar, M. H. (2017). Estimates and 25-year trends of the global burden of disease attributable to ambient air pollution: an analysis of data from the Global Burden of Diseases Study 2015. Lancet, 389(10082), 1907-1918. https://doi.org/10.1016/S0140-6736(17)30505-6.

Cracknell, A. P., \& Varotsos, C. A. (2011). New aspects of global climate-dynamics research and remote sensing. International Journal of Remote Sensing, 32(3), 579-600. https://doi. org/10.1080/01431161.2010.517807.

Cracknell, A. P., \& Varotsos, C. A. (2007). Editorial and cover: Fifty years after the first artificial satellite: from Sputnik 1 to ENVISAT. International Journal of Remote Sensing, 28(10), 2071-2072. https://doi.org/10.1080/01431160701347147.

Dutheil, F., Baker, J. S., \& Navel, V. (2020). COVID-19 as a factor influencing air pollution? Environmental Pollution, 263, 114466. https://doi.org/10.1016/j.envpol.2020.114466.

Efstathiou, M. N., \& Varotsos, C. A. (2010). On the altitude dependence of the temperature scaling behaviour at the global troposphere. International Journal of Remote Sensing, 31(2), 343-349

Efstathiou, M. N., \& Varotsos, C. A. (2012). Intrinsic properties of Sahel precipitation anomalies and rainfall. Theoretical and Applied Climatology, 109(3), 627-633

Efstathiou, M. N., Tzanis, C., Cracknell, A. P., \& Varotsos, C. A. (2011). New features of land and sea surface temperature anomalies. International journal of remote sensing, 32(11), 3231-3238

He, M. Z., Kinney, P. L., Li, T., Chen, C., Sun, Q., Ban, J., Wang, J., Liu, S., Goldsmith, J., \& Kioumourtzoglou, M.-A. (2020). Short- and intermediate-term exposure to $\mathrm{NO} 2$ and mortality: A multi-county analysis in China. Environmental Pollution, 261, 114165. https://doi.org/10.1016/j.envpol.2020.114165.

Huang, C., Wang, Y., Li, X., Ren, L., Zhao, J., Hu, Y., Zhang, L., Fan, G., Xu, J., Gu, X., Cheng, Z., Yu, T., Xia, J., Wei, Y., Wu, W., Xie, X., Yin, W., Li, H., Liu, M., Xiao, Y., Gao, H., Guo, L., Xie, J., Wang, G., Jiang, R., Gao, Z., Jin, Q., Wang, J., \& Cao, B. (2020). Clinical features of patients infected with 2019 novel coronavirus in Wuhan, China. The Lancet, 395(10223), 497-506. https://doi.org/10.1016/S0140-6736 (20)30183-5.

NASA (2020) Nitrogen dioxide levels rebound in China. In: NASA Earth Obs. https://earthobservatory.nasa. gov/images/146741/nitrogen-dioxide-levels-rebound-inchina. Accessed 20 Sep 2020

Ortiz, C., Linares, C., Carmona, R., \& Díaz, J. (2017). Evaluation of short-term mortality attributable to particulate matter pollution in Spain. Environmental Pollution, 224, 541-551. https://doi.org/10.1016/j.envpol.2017.02.037.

Rohde, R. A., \& Muller, R. A. (2015). Air pollution in China: Mapping of concentrations and sources. PLoS ONE, 10(8), e0135749. https://doi.org/10.1371/journal.pone.0135749.

Schiermeier, Q. (2020). Why pollution is plummeting in some cities - but not others. Nature, 580(7803), 313-313. https://doi.org/10.1038/d41586-020-01049-6.

Setti L, Passarini F, de Gennaro G, Di Gilio A, Palmisani J, Buono P, Fornari G, Perrone MG, Piazzalunga A, Barbieri P, Rizzo E, Miani A (2020) Evaluation of the potential relationship between particulate matter (PM) pollution and COVID-19 infection spread in italy

Varotsos, C., \& Cartalis, C. (1991). Re-evaluation of surface ozone over Athens, Greece, for the period 1901-1940. Atmospheric Research, 26(4), 303-310. https://doi. org/10.1016/0169-8095(91)90024-Q.

Varotsos, C., Christodoulakis, J., Tzanis, C., \& Cracknell, A. P. (2014). Signature of tropospheric ozone and nitrogen dioxide from space: A case study for Athens, Greece. Atmospheric Environment, 89, 721-730. https://doi.org/10.1016/j. atmosenv.2014.02.059.

Varotsos, C. A., \& Krapivin, V. F. (2020). A new model for the spread of COVID-19 and the improvement of safety. Safety Science, 132, 104962. https://doi.org/10.1016/j. ssci.2020.104962.

Varotsos, C. A., Krapivin, V. F., \& Xue, Y. (2021). Diagnostic model for the society safety under Covid-19 pandemic conditions. Safety Science, 105164. https://doi.org/10.1016/j. ssci.2021.105164.

Varotsos, C. A., Efstathiou, M. N., \& Cracknell, A. P. (2013). On the scaling effect in global surface air temperature anomalies. Atmospheric Chemistry and Physics, 13(10), 5243-5253

Wang, H., Dwyer-Lindgren, L., Lofgren, K. T., Rajaratnam, J. K., Marcus, J. R., Levin-Rector, A., Levitz, C. E., Lopez, A. D., \& Murray, C. J. (2012). Age-specific and sex-specific mortality in 187 countries, 1970-2010: A systematic analysis for the Global Burden of Disease Study 2010. The Lancet, 380(9859), 2071-2094. https://doi.org/10.1016/S0140-6736 (12)61719-X.

Publisher's Note Springer Nature remains neutral with regard to jurisdictional claims in published maps and institutional affiliations. 